\title{
Successive oligopolies and decreasing returns
}

\author{
J.J. Gabszewicz and Sk. Zanaj
}

Discussion Paper 2008-33

Département des Sciences Économiques

de l'Université catholique de Louvain 


\title{
CORE DISCUSSION PAPER
}

$2008 / 50$

\section{Successive oligopolies and decreasing returns}

\section{Jean J. GABSZEWICZ ${ }^{1}$ and Skerdilajda ZANAJ ${ }^{2}$}

August 2008

\begin{abstract}
In this paper, we propose an example of successive oligopolies where the downstream firms share the same decreasing returns technology of the Cobb-Douglas type. We stress the differences between the conclusions obtained under this assumption and those resulting from the traditional example considered in the literature, namely, a constant returns technology.
\end{abstract}

Keywords: successive oligopolies, vertical integration, technology.

JEL Classification: D43, L1, L22, L42

${ }^{1}$ CORE, Université catholique de Louvain, Belgium.E-mail: jean-gabszewicz@uclouvain.be.

${ }^{2}$ CORE, Université catholique de Louvain, Belgium and Université du Luxembourg.

This paper presents research results of the Belgian Program on Interuniversity Poles of Attraction initiated by the Belgian State, Prime Minister's Office, Science Policy Programming. The scientific responsibility is assumed by the authors. 


\section{Introduction}

The literature on successive oligopolies is traditionally based on examples, concerning the technology used by firms to produce the final output: downstream firms are assumed to have the same linear technology using a single input. In this paper, we go on with this tradition, but now introduce the alternative assumption that downstream firms share the same decreasing returns technology. Here we assume that the Cobb-Douglas production function $f(z)=\sqrt{z}$, with $z$ denoting the amount of input, is used in the production process. Our main concern is whether the major conclusions reached under constant returns still hold when a decreasing returns technology is substituted to the linear one.

Comparing this solution with the linear case, it turns out that several features are different from those observed under constant returns. First, we show that double marginalisation is less severe under decreasing returns than under constant returns, reflecting the fact that the cost per unit is higher in the latter than in the former. Second, we prove that, contrary to intuition, the profit of a downstream firm, under a decreasing returns technology, may be decreasing with the number of upstream firms. On the contrary, this cannot happen under a constant returns technology. Moreover, we find that, in contrast with the linear case, increasing simultaneously the number of firms in both markets (upstream and downstream), does not let the input market price to converge to the competitive one, namely the marginal cost of producing the input. Finally, we compare the effects of mergers under both assumptions fixing the number of firms in each market. For this particular example the effects of vertical integration on prices are going in opposite directions according as we assume a linear, or a decreasing returns, technology. While the input and output prices both increase in the former when vertical integration takes place, both decrease in the latter.

The above discrepancies between market behaviour corresponding to alternative technological conditions reveal how fragile are the theoretical conclusions obtained when analysing the interplay of firms' strategies in successive markets. To get robust conclusions, a general theoretical framework for analysing successive oligopolistic markets is clearly required.

The paper is organized as follows. In the next section, we develop two games, one in the dowsntream and the other in the upstream market, to obtain the industry equilibria. In section 2, according to the technology used in the downstream market, we analyse the effects of number of firms in profits, the asymptotic properties of input and output prices, the size of double marginalization, and finally, the effects of technology on collusive agreements. Section 3 concludes. 


\section{Industry equilibria under decreasing returns}

In this section, we develop the procedure through which prices and quantities obtain in each market, downstream and upstream. This procedure is identical to the method implicitly followed in the example considered in the literature on successive oligopolies under constant returns, like Gaudet and Van Long (1996), Ordover et al (1990), or Salinger (1988). There are two markets, the downstream and upstream ones, with identical firms in each of them. In these markets, firms select non cooperatively the quantities of output of the good they produce, the output of the upstream firms serving as the only input used in the production of the output in the downstream market. The link between the two markets follows from the fact that the downstream firms' unit cost appears as the unit revenue for the upstream ones : the price paid for a unit of input for the firms in the former constitutes the unit receipt for the firms in the latter. Furthermore, we keep most of the traditional assumptions used in the constant returns example proposed by the literature: linear demand in the downstream market, identical production function for the downstream firms and identical linear total cost for the upstream firms. Also we assume, as usual, that downstream firms are price takers in the input market. Thus, we keep completely in line with the traditional example considered in the literature on successive oligopolies, but one : the production function of the downstream is no longer linear, but with decreasing returns.

Formally, consider $n$ downstream firms facing the linear demand $\pi(Q)=$ $1-Q$ in the downstream market.All of them share the same technology $f(z)$ to produce the output, namely

$$
q=f(z)=\sqrt{z}
$$

We assume that this situation gives rise to a game, whose players are the $n$ downstream firms with output strategies $q_{i}$.

The profits of the $i_{t h}$ downstream firm at the vector of strategies $\left(q_{i}, q_{-i}\right)$ obtains as

$$
\Pi_{i}\left(q_{i}, q_{-i}\right)=\left(1-q_{i}-\Sigma_{k \neq i} q_{k}\right) q_{i}-p q_{i}^{2} .
$$

Given a vector of strategies $\left(q_{1}, \ldots q_{i}, . . q_{n}\right)$, the resulting input demand $\sum_{k=1}^{n} z_{k}(p)$ in the upstream market obtains as

$$
\Sigma_{k=1}^{n} z_{k}(p)=\Sigma_{k=1}^{n} q_{k}^{2}
$$

Now assume that there are $m$ identical upstream firms who produce the input $z$ at the same linear total cost $\beta s_{j}, j=1, . ., m, \beta>0$. This gives rise to another game whose players are the $m$ upstream firms with strategies $s_{j}, j=1, . . m$.

Given a vector of strategies $\left(s_{1}, \ldots s_{j}, . . s_{m}\right)$, the $j_{t h}$ upstream firm's profit $\Gamma_{j}$ writes as

$$
\Gamma_{j}\left(s_{j}, s_{-j}\right)=p\left(s_{j}, s_{-j}\right) s_{j}-\beta s_{j} .
$$


Given an $n$-tuple of strategies $\left(q_{1}, \ldots q_{i}, . . q_{n}\right)$ and a $m$-tuple of strategies $\left(s_{1}, \ldots s_{j}, . . s_{m}\right)$, we may compute the symmetric Nash equilibrium of each of the above games under the condition that the input price balances supply and demand in the input market. The explicit values of the symmetric Nash equilibrium in each of the above games are derived in Appendix 1.

Denoting $\left(q^{*}(p), \ldots q^{*}(p), . . q^{*}(p)\right)$ and $\left(s^{*}(p), \ldots s^{*}(p), . . s^{*}(p)\right)$ the symmetric solution of each game, they must satisfy the equality

$$
n\left(q^{*}(p)\right)^{2}=m s^{*}(p) .
$$

\section{Number of firms and profits}

\subsection{Number of upstream firms and downstream profits}

In this section, we compare how the profits of both downstream and upstream firms depend on the technology used to produce the final output and on the number of firms. Under oligopoly and linear output demand, decreasing linear production cost must necessarly increase downstream firms' profits. Accordingly, since increasing the number of upstream firms leads to a decrease in the input price, the profit of downstream oligopolists, must necessarly increase under a constant returns technology. The first question we would like to raise is whether this simple reasoning still applies when returns are decreasing. It turns out that this is not always the case.

Proposition 1 The profit of a downstream firm may decrease if the competition in the upstream market is fiercer. For instance, when the number of firms in the dowsntream market does not exceed 3, profits of a dowsntream firm always decreases when the number of upstream firms increases.

Proof. see appendix 3.

Kurz (1982) and Seade (1985) have shown that, under Cournot oligopoly, it is not necessarly true that a decrease of production cost leads to an increase of profits, a proposition analogous to ours. When the number of upstream firms decreases, competition becomes fiercer in the upstream market and the input price must necessarly decrease, increasing thereby the production cost of dowsntream firms. In this case, we are back to Kurz and Seade effect: decreasing competition in the upstream market does not necessarly entail higher profits for the downstream firms. While it would never happen under constant returns that lower profits would be observed at the equilibrium of the downstream market, it can happen in the case of decreasing returns ${ }^{1}$.

Consider the profit function of a downstream firm, $\Pi_{i}=\pi(m, n) f(z(m, n))-$ $p(m, n) z(m, n)$, under the alternative assumptions $f(z)=\sqrt{z}$ or $f(z)=z$.

\footnotetext{
${ }^{1}$ Seade (1985) uses conditions on the elasticity on the market demand function to identify when decreasing cost can increase profits. In our case, this condition bears on technology and the relative number of firms, $m$ and $n$, in the markets.
} 
Clearly,

$$
\frac{\partial \Pi_{i}}{\partial m}=\frac{\partial \pi}{\partial m} f(z)+\frac{\partial f}{\partial z} \frac{\partial z}{\partial m} \pi-\left(\frac{\partial p}{\partial m} z+\frac{\partial z}{\partial m} p\right) .
$$

Comparing the values of $\frac{\partial \Pi_{i}}{\partial m}$ under the two alternative assumptions, they differ only by the fact that technologies differ from each other. With decreasing returns, the final effect on the downstream profit can be of either sign because the effect on the revenue incorporates the non-linear marginal productivity $\frac{\partial f}{\partial z}=\frac{1}{2 \sqrt{z}}$, of the input $z$. By constrast, when marginal productivity remains constant, as in the linear technology, the effect on cost of an increasing number of upstream firms always dominates its effect on revenues.

\subsection{Asymptotic properties of input and output prices}

It is interesting to analyse output and input prices when the number of firms in each market is increased without limit. We should expect that, asympotically, both these prices should tend to the corresponding marginal costs. While this property indeed holds under a linear technology, it fails to hold under the decreasing returns. In order to show this property we use a replication procedure introduced by Debreu and Scarf (1963) in the framework of a pure exchange economy. Let us replicate $r$ times the basic economy as described above. Namely, in the $r$-th replica, downstream market demand is given by $r(1-Q)$ and there are $r n$ downstream and $r m$ upstream firms. Using formulas (), () in the appendix 1, we notice that, in the $r_{t h}$-replica, the prices at which demand is equal to supply both in the downstream and upstream markets, do not depend on the number $r$, but depend only on $m$ and $n$. Indeed, at the symmetric equilibrium in the upstream market, the input quantities supplied by the $m$ upstream firms have to be multiplied by $r$ in the $r_{t h}$-replica; similarly for the quantities demanded by the $n$ downstream firms in the downstream market. Consequently, the equality of supply and demand in the upstream market eliminates the $r$ - factor in each side of the equality. A similar reasoning applies for the symmetric price equilibrium in the downstream market. It follows that the study of the behaviour of the upstream and downstream markets when the number of replications increases is equivalent to the study of the limit equilibrium prices and quantities, when the number of firms is $r n$ and $r m$, instead of $n$ and $m$, in each market, respectively. This replication procedure thus leads to increase, simultaneously and at the same speed, the number of firms in each market. Contrary to intuition, we show in the next proposition that the input price does not converge to its marginal cost under decreasing returns.

Proposition 2 Under decreasing returns (resp. constant returns), when the number of replications of the basic economy tends to $\infty$, the equilibrium input price does not (resp. does) converge to upstream firms' marginal cost.

Proof. see Appendix 3. 
The intuition of this proposition can be described as follows. Under decreasing returns, when the number of replicas is increased, the equilibrium quantity produced by each downstream firm, tends to zero. Accordingly, the marginal productivity of input tends itself to infinity, making impossible the equality of supply and demand in the upstream market. The volume of input demand can be balanced with the input supply only by dampening demand with a price which remains strictly higher than the marginal cost of producing the input, whatever the number of replications ${ }^{2}$. In the linear case, marginal productivity remains constant when the number of replications increases, which prevents a similar phenomenon to arise.

\subsection{Double marginalization under constant vs decreasing returns}

We now briefly address the size of double marginalization according to the type of technology used by downstream firms to produce the output: decreasing or constant returns. Double marginalization is defined as the sum of the markup exercised by the upstream firms, $p^{*}-\beta$, and the markup applied by the downstream firms, $\pi^{*}-p^{*}$, which yields $\pi^{*}-\beta$. Therefore, to compare double marginalization according to the downstream technology, we compare output prices under the two technologies. From the direct comparison of output prices we obtain that:

Proposition 3 Double marginalization is lower when downstream firms use decreasing returns than when they use constant returns technology.

Proof. see Appendix 3.

\subsection{The effects of technology on collusive agreements}

Collusive agreements between upstream and dowsntream firms eliminate double marginalization, which yields to lower prices for the consumers of the final product. On the other hand, these vertical integration agreements can lead to foreclosure of rivals firms in the downstream market, which has the opposite effect on the price of the final product. Finally, the global effect depends on the size of double marginalization; which itself depends, as shown before, on the technology used by the downstream firms. In this section, we use the above example of decreasing returns technology in successive oligopolies, to analyse and compare the effects of vertical integration according to the technology used in the downstream market.

Collusive agreements reduces the total number of decision units operating in the downstream and upstream markets and, thus, the corresponding number of oligopolists in each of them (see Salant, Schwitzer and Reynolds (1983)).

\footnotetext{
${ }^{2}$ It would be interesting to extend this result to the general class of decreasing returns CobbDouglas production functions $f(z)=z^{\alpha}, \alpha<1$. Unfortunately, it turns out the solutions of the model leads to combersome computations when $\alpha \neq \frac{1}{2}$.
} 
Collusive outcomes are the Cournot equilibria corresponding to this reduced number of oligopolists in each market.

Assume that $k$ downstream firms $i, i=1, \ldots, k$, say, and $h$ upstream firms $j, j=1, \ldots, h$, say, collude and maximize joint profits (notice that all firms, $h+k$, merge in one entity). We assume that $k<n$ and $h<m^{3}$. After this merger, we move from an initial situation comprising globally $n+m$ firms to a new one, with $n-k+1$ firms in the downstream market and $m-h$ in the upstream one. Indeed, the integrated entity now internalizes output production by using the input provided by the $h$ upstream firms belonging to the new entity. This general formulation covers as particular cases mergers including either only downstream firms, or only upstream ones, which correspond to the usual case of horizontal merging of firms.

The payoff of the integrated firm $I$ is given by

$$
\Pi_{I}\left(q_{I}, q_{-I}\right)=\left(1-q_{I}-\sum_{k \neq I} q_{k}\right) q_{I}-\beta q_{I}^{2}
$$

where $q_{I}$ denotes the quantity of output produced by the integrated entity. As for the downstream firms $i, i \neq I$, not belonging to the integrated entity, they have as payoffs ${ }^{4}$

$$
\left.\Pi_{i}\left(q_{i}, q_{I}, q_{-i}\right)=\left(1-q_{i}-\sum_{k \neq i}^{n} q_{k}\right) q_{i}-p q_{i}^{2}\right)
$$

Following the upstream and the downstream games explained in section (2), we derive in Appendix 4, the equilibrium output and input quantities and prices, for the entity of $h+k$ firms and the non-integrated upstream and downstream firms. Comparing these variables with those obtained when dowsntream firm use a linear technology, it is possible to analyse how collusive agreements can be affected by technology.

First, in Gabszewicz and Zanaj (2007) we show in an illustration with two downstream and three upstream firms, that a collusive agreement between one downstream and one upstream firm can have diametrically opposite consequences depending whether the technology is constant, or decreasing returns. In the first case, the collusive agreement leads to a decrease of both the input and output prices, while the reverse holds under decreasing returns. On the other hand, the profitability of mergers also depends on technology. Indeed, with cosntant returns, it can be shown that when $n=m=7$, only vertical integration of one downstream and one upstream firm, $1: 1$, can be profitable. Similarly, for $m=n=10$, the only profitable mergers are $1: 1$ and $2: 2$. Finally, in all these profitable vertical integrations, the conseguence is higher input and output price. These results are very different from those obtained

\footnotetext{
${ }^{3}$ This assumption guarantees that there always exists at least one unintegrated firm on each side of the upstream market so that the integrated entity cannot exclude the unintegrated downstream firms to have access to the input. A similar assumption in another approach to collusion has been used by Gabszewicz and Hansen (1972).

${ }^{4}$ Notice that the set $\{k: k \neq i\}$ includes the index $I$.
} 
when firms in the downstream firm use constant returns as in Salinger (1988). For the same parametric values, Salinger (1988) shows that vertical integration can determine lower output prices, and also, the number of profitable mergers is much larger.

\section{Conclusion}

In this paper, we propose an example of successive oligopolies where the downstream firms share the same decreasing returns technology of the Cobb-Douglas type. We stress the differences between the conclusions obtained under this assumption and those resulting from the traditional example considered in the literature, namely, a constant returns technology. We find that when firms use a decreasing returns technology rather than a linear one: (i) the profit of a downstream firm can increase, when the upstream market is more competitive; (ii) the input price does not tend to the corresponding marginal cost when the number of firms in both markets tends to infinite; (iii) double marginalization is lower and, finally, (iv) vertical integration arises less frequently, and leads to higher prices for final consumers. These discrepancies between market behavior corresponding to alternative technological conditions reveal how fragile are the theoretical conclusions obtained when analyzing the interplay of firms' strategies in successive markets only using a linear technology in the downstream market, as it is done so far in the literature. To get robust conclusions, a general theoretical framework for analyzing successive oligopolistic markets should clearly be required.

\section{References}

[1] Debreu G. and Scarf H., "A Limit Theorem on the Core of an Economy", 1963, International Economic Review, Vol. 4, 235-246

[2] Gabszewicz J. J. and Zanaj S., 2007, A note on vertical mergers and successive oligopolies, Communication and strategies, Volume 4th quarter 2007, Issue: 68 .

[3] Gaudet G. and Van Long N., "Vertical Integration, Foreclosure and Profits in the Presence of Double Marginalisation", Journal of Economics and Management Strategy, 1996, Vol. 5(3), 409-432

[4] Hansen, T. and Gabszewicz, J., 1972. "Collusion of factor owners and distribution of social output," Journal of Economic Theory, Elsevier, vol. 4(1), pages 1-18, February.

[5] Ordover, J. and Saloner, G. and Salop, S.: "Equilibrium vertical foreclosure", The American Economic Review, 1990, Vol. 80, 127-142

[6] Kurz M, 1982, Cooperative oligopoly equilibrium, Standford Working papers, 383 
[7] Salant S., Schwitzer Sh. and Reynolds R. , "Losses from Horizontal Merger: The Effects of an Exogenous Change in Industry Structure on Cournot-Nash Equilibrium, The Quarterly Journal of Economics, 1983, Vol. 98, 185-99

[8] Salinger M., "Vertical mergers and market foreclosure", The Quartely Journal of Economics, 1988, Vol. 103, 345-356

[9] Seade J, 1985, "Profitable cost increases and the shifting of taxation : equilibrium responses of markets in oligopoly", Warwick discussion papers, $\mathrm{n}$ 260 .

\section{Appendix 1: Decreasing returns technology}

In this section of the Appendix we derive the equilibrium quantities and prices when downstream firms use decreasing returns technology. The profits of the $i_{t h}$ downstream firm at the vector of strategies $\left(q_{i}, q_{-i}\right)$ obtains as

$$
\Pi_{i}\left(q_{i}, q_{-i}\right)=\left(1-q_{i}-\Sigma_{k \neq i} q_{k}\right) q_{i}-p q_{i}^{2} .
$$

Taking the first derivative and solving it in $q$, we get at the symmetric solution

$$
q^{*}(p)=\frac{1}{(n+2 p+1)} ; i=1 \ldots n .
$$

Similarly, re-expressing equation (??), and solving it for $s$, we obtain

$$
s^{*}(p)=\frac{\beta-p\left(m s^{*}\right)}{\partial p(m s) / \partial s} .
$$

The input price $p^{*}$ must satisfy the system of equations $n\left(q^{*}(p)\right)^{2}=m s^{*}(p)$, (??) and (??). To derive the explicit equilibrium price, we can proceed as follows. First, we identify the total demand for input at the symmetric solution of the first game, using (??) namely $\frac{n}{(n+2 p+1)}$. Then, using the input clearing market condition, the equality $\frac{n}{(n+2 p+1)^{2}}=\Sigma_{k=1}^{m} s_{k}(p)$ has to be satisfied at any vector of strategies $\left(s_{1}, \ldots, s_{j}, . . s_{m}\right)$ in the input market. Accordingly, the equality

$$
p\left(\sum_{k=1}^{m} s_{k}\right)=\sqrt{\frac{n}{4 \sum_{k=1}^{m} s_{k}}}-\frac{n+1}{2} .
$$

must hold for any vector of strategies in the input market. Substituting (??) into the profit function of an upstream firm, $\Gamma_{j}\left(s_{j}, s_{-j}\right)$ we have

$$
\Gamma_{j}\left(s_{j}, s_{-j}\right)=\left(\sqrt{\frac{n}{4 \sum_{k=1}^{m} s_{k}}}-\frac{n+1}{2}\right) s_{j}-\beta s_{j},
$$

Notice that the profit function $\Gamma_{j}\left(s_{j}, s_{-j}\right)$ is concave in $s_{j}, j=1, \ldots m$, so that we can use the first order necessary and sufficient conditions to characterize an 
equilibrium. Accordingly, at the symmetric Nash equilibrium of the upstream game, we obtain

$$
s^{*}(m, n)=\frac{n(2 m-1)^{2}}{4 m^{3}(2 \beta+1+n)^{2}} .
$$

Hence the profit $\Gamma_{j}(m, n)$ of an upstream firm at the symmetric equilibrium of the upstream game obtains as

$$
\Gamma_{j}(m, n)=\frac{n(2 m-1)}{8(n+2 \beta+1) m^{3}} .
$$

Finally, the equilibrium price $p^{*}(m, n)$ in the input market obtains as

$$
p^{*}(m, n)=\frac{n+1+4 m \beta}{2(2 m-1)} .
$$

Consequently, substituting this equilibrium price into the equilibrium quantities $q^{*}$ of output selected by the downstream firms, as given by (??), we get

$$
q^{*}(m, n)=\frac{2 m-1}{2 m(2 \beta+n+1)}
$$

so that, given the technology, the equilibrium input quantities used by downstream firms writes as

$$
z^{*}(m, n)=\frac{(2 m-1)^{2}}{4 m^{2}(2 \beta+n+1)^{2}}
$$

Therefore, the resulting output price $\pi^{*}(m, n)$ in the downstream market obtains as

$$
\pi^{*}(m, n)=1-\frac{n(2 m-1)}{2 m(2 \beta+n+1)} .
$$

The profit $\Pi_{i}(m, n)$ of a downstream firm at equilibrium in the corresponding game is thus equal to

$$
\Pi_{i}(m, n)=\frac{1}{8}(4 m \beta+4 m+n-1) \frac{2 m-1}{m^{2}(2 \beta+n+1)^{2}} .
$$

Notice that $\Pi_{i}>0$, - a requirement needed to guarantee the survival of firms in the downstream market.

\section{Appendix 2: Constant returns technology}

We consider exactly the same case as in appendix 1, with the exception that the technology $f(z)$ shared by the downstream firms is now given by

$$
f(z)=\alpha z, \alpha>0
$$


as in Salinger and Gaudet and Van Long (with $\alpha$ equal to 1 in the latter case).We assume that $\alpha \geq \beta$ : this assumption guarantees that the marginal cost of producing the input does not exceed its marginal product in the production of output. The profits $\Pi_{i}\left(q_{i}, q_{-i}\right)$ of the $i_{t h}$ downstream firm at the vector of strategies $\left(q_{i}, q_{-i}\right)$ now obtains as

$$
\Pi_{i}\left(q_{i}, q_{-i}\right)=\left(1-q_{i}-\Sigma_{k \neq i} q_{k}\right) q_{i}-p z_{i} .
$$

The payoff function $\Gamma_{j}\left(s_{j}, s_{-j}\right)$ of the $j_{t h}$ upstream firms writes as we have

$$
\Gamma_{j}\left(s_{j}, s_{-j}\right)=p\left(s_{j}, s_{-j}\right) s_{j}-\beta s_{j} .
$$

Accordingly, closely following the above section, or the exisiting papers using constant returns technology (see Salinger (1988) or Gaudet and Van Long (1996)), at the symmetric equilibrium of the second stage game, the individual input supply writes as

$$
s^{*}(m, n)=\frac{n(\alpha-\beta)}{\alpha^{2}(n+1)(m+1)},
$$

so that the equilibrium price in the input market obtains as

$$
p^{*}(m, n)=\frac{\alpha+m \beta}{m+1} .
$$

Consequently, substituting this equilibrium price into the quantities $z_{i}^{*}$ of input bought by each downstream firm, we get

$$
z^{*}(m, n)=\frac{m(\alpha-\beta)}{\alpha^{2}(n+1)(m+1)},
$$

so that

$$
q_{i}^{*}(m, n)=\frac{m(\alpha-\beta)}{\alpha(n+1)(m+1)} .
$$

Accordingly, the resulting output price $\pi^{*}(m, n)$ in the downstream market obtains as

$$
\pi^{*}(m, n)=\frac{\alpha(1+m+n)+m n \beta}{\alpha(n+1)(m+1)} .
$$

\subsection{Appendix 3: Proofs of propositions}

Proposition 1: The profit of a downstream firm may decrease if the competition in the upstream market is fiercer. For instance, when the number of firms in the dowsntream market does not exceed 3, profits of a dowsntream firm always decreases when the number of upstream firms increases.

Proof. The derivative of the profit of a downstream firm is $\frac{3 m+n-m n-1+2 m \beta}{4(n+1)^{2} m^{3}}$. Hence, the sign depends only on the sign of the numerator, $3 m+n-m n-1+2 m \beta$. 
The derivative is positive iff $m<\frac{1-n}{2 \beta+3-n}$, and negative iff $m>\frac{1-n}{2 \beta+3-n}$. It is immediate that the last expression is always true for $\beta>\frac{n-3}{2}$.

Proposition 2: Under decreasing returns (resp. constant returns), when the number of replications of the basic economy tends to $\infty$, the equilibrium input price does not (resp. does ) converge to upstream firms' marginal cost.

Proof. We consider the situation where the number of replicas $r$ tends to infinite. So, we calculate the limit for $r \rightarrow+\infty$ of the expression of the input price:

Proof.

$$
\lim _{r \rightarrow \infty} p^{*}(r m, r n)=\frac{1}{4} \frac{n}{m}+\beta
$$

Proof. Clearly, the price $p^{*}$ at the limit does not converge to $\beta$, unless $m$ converges to infinite more quickly than $n$.

Proposition 3:Double marginalization is lower when downstream firms use decreasing returns than when they use constant returns technology.

Proof. Consider $\frac{\alpha(1+m+n)+m n \beta}{\alpha(n+1)(m+1)}+\frac{n(2 m-1)}{2 m(2 \beta+n+1)}<1$. We prove that the inequality

is false. It is easy to check that the first derivative with respect to $\alpha$ of each side of the left hand side of the inequality is negative. We know that $\beta<\alpha$. Therefore, assuming $\alpha=\beta$, we can consider the inequaltiy $\frac{\beta(1+m+n)+m n \beta}{\beta(n+1)(m+1)}+$ $\frac{n(2 m-1)}{2 m(2 \beta+n+1)}<1$ where we just make the left hand side bigger. The solution of such inequality is a subset of the original inequality.

Solving for $\beta$, we find that it is true only for $\beta<0$. This is not an admissible set of $\beta$, therefore the inequality is false, and the price with decreasing returns technology is smaller than the price with constant returns.

\subsection{Appendix 4: Vertical integration solution}

Following the solution of the game in the benchmark model, at the symmetric equilibrium in the upstream market, each unintegrated firm supplies a quantity $s_{j}^{*}$ of input which obtains as

$$
s^{*}(k, h)=\frac{1}{4} \frac{(2 m-2 h-1)^{2}(n-k)}{(n-k+2 \beta+2)^{2}(m-h)^{3}} .
$$

while the input price writes as

$p^{*}(k, h)=\frac{1}{4(\beta+1)}\left((n-k+2 \beta+2)\left(2(2 \beta+1)(m-h)^{2}-1\right)-2 \beta(n-k)\right)$.

Then, substituting $p^{*}$ in the expression of $q_{i}$ and $q_{I}$, we obtain

$$
\begin{aligned}
q_{i}(k, h) & =\frac{1}{2(n-k+2 \beta+2)(m-h)^{2}}, \\
q_{I}(k, h) & =\frac{2(n-k+2 \beta+2)(m-h)^{2}-(n-k)}{4(n-k+2 \beta+2)(\beta+1)(m-h)^{2}} .
\end{aligned}
$$


The price of the output then obtains as

$$
\begin{aligned}
\pi^{*}(k, h)= & \left(1-\frac{1}{2(n-k+2 \beta+2)(m-h)^{2}}(n-k)\right. \\
& \left.-\frac{2(n-k+2 \beta+2)(m-h)^{2}-(n-k)}{4(n-k+2 \beta+2)(\beta+1)(m-h)^{2}}\right) .
\end{aligned}
$$




\section{Recent titles}

\section{CORE Discussion Papers}

2008/13. Loran CHOLLETE, Andréas HEINEN and Alfonso VALDESOGO. Modeling international financial returns with a multivariate regime switching copula.

2008/14. Filomena GARCIA and Cecilia VERGARI. Compatibility choice in vertically differentiated technologies.

2008/15. Juan D. MORENO-TERNERO. Interdependent preferences in the design of equal-opportunity policies.

2008/16. Ana MAULEON, Vincent VANNETELBOSCH and Wouter VERGOTE. Von NeumannMorgenstern farsightedly stable sets in two-sided matching.

2008/17. Tanguy ISAAC. Information revelation in markets with pairwise meetings: complete information revelation in dynamic analysis.

2008/18. Juan D. MORENO-TERNERO and John E. ROEMER. Axiomatic resource allocation for heterogeneous agents.

2008/19. Carlo CAPUANO and Giuseppe DE FEO. Mixed duopoly, privatization and the shadow cost of public funds.

2008/20. Helmuth CREMER, Philippe DE DONDER, Dario MALDONADO and Pierre PESTIEAU. Forced saving, redistribution and nonlinear social security schemes.

2008/21. Philippe CHEVALIER and Jean-Christophe VAN DEN SCHRIECK. Approximating multiple class queueing models with loss models.

2008/22. Pierre PESTIEAU and Uri M. POSSEN. Interaction of defined benefit pension plans and social security.

2008/23. Marco MARINUCCI. Optimal ownership in joint ventures with contributions of asymmetric partners.

2008/24. Raouf BOUCEKKINE, Natali HRITONENKO and Yuri YATSENKO. Optimal firm behavior under environmental constraints.

2008/25. Ana MAULEON, Vincent VANNETELBOSCH and Cecilia VERGARI. Market integration in network industries.

2008/26. Leonidas C. KOUTSOUGERAS and Nicholas ZIROS. Decentralization of the core through Nash equilibrium.

2008/27. Jean J. GABSZEWICZ, Didier LAUSSEL and Ornella TAROLA. To acquire, or to compete? An entry dilemma.

2008/28. Jean-Sébastien TRANCREZ, Philippe CHEVALIER and Pierre SEMAL. Probability masses fitting in the analysis of manufacturing flow lines.

2008/29. Marie-Louise LEROUX. Endogenous differential mortality, non monitored effort and optimal non linear taxation.

2008/30. Santanu S. DEY and Laurence A. WOLSEY. Two row mixed integer cuts via lifting.

2008/31. Helmuth CREMER, Philippe DE DONDER, Dario MALDONADO and Pierre PESTIEAU. Taxing sin goods and subsidizing health care.

2008/32. Jean J. GABSZEWICZ, Didier LAUSSEL and Nathalie SONNAC. The TV news scheduling game when the newscaster's face matters.

2008/33. Didier LAUSSEL and Joana RESENDE. Does the absence of competition in the market foster competition for the market? A dynamic approach to aftermarkets.

2008/34. Vincent D. BLONDEL and Yurii NESTEROV. Polynomial-time computation of the joint spectral radius for some sets of nonnegative matrices.

2008/35. David DE LA CROIX and Clara DELAVALLADE. Democracy, rule of law, corruption incentives and growth.

2008/36. Jean J. GABSZEWICZ and Joana RESENDE. Uncertain quality, product variety and price competition. 2008/37. Gregor ZOETTL. On investment decisions in liberalized electricity markets: the impact of price caps at the spot market.

2008/38. Helmuth CREMER, Philippe DE DONDER, Dario MALDONADO and Pierre PESTIEAU. Habit formation and labor supply. 


\section{Recent titles}

\section{CORE Discussion Papers - continued}

2008/39. Marie-Louise LEROUX and Grégory PONTHIERE. Optimal tax policy and expected longevity: a mean and variance approach.

2008/40. Kristian BEHRENS and Pierre M. PICARD. Transportation, freight rates, and economic geography.

2008/41. Gregor ZOETTL. Investment decisions in liberalized electricity markets: A framework of peak load pricing with strategic firms.

2008/42. Raouf BOUCEKKINE, Rodolphe DESBORDES and Hélène LATZER. How do epidemics induce behavioral changes?

2008/43. David DE LA CROIX and Marie VANDER DONCKT. Would empowering women initiate the demographic transition in least-developed countries?

2008/44. Geoffrey CARUSO, Dominique PEETERS, Jean CAVAILHES and Mark ROUNSEVELL. Space-time patterns of urban sprawl, a 1D cellular automata and microeconomic approach.

2008/45. Taoufik BOUEZMARNI, Jeroen V.K. ROMBOUTS and Abderrahim TAAMOUTI. Asymptotic properties of the Bernstein density copula for dependent data.

2008/46. Joe THARAKAN and Jean-Philippe TROPEANO. On the impact of labor market matching on regional disparities.

2008/47. Shin-Huei WANG and Cheng HSIAO. An easy test for two stationary long processes being uncorrelated via AR approximations.

2008/48. David DE LA CROIX. Adult longevity and economic take-off: from Malthus to Ben-Porath.

2008/49. David DE LA CROIX and Gregory PONTHIERE. On the Golden Rule of capital accumulation under endogenous longevity.

2008/50. Jean J. GABSZEWICZ and Skerdilajda ZANAJ. Successive oligopolies and decreasing returns.

\section{Books}

Y. POCHET and L. WOLSEY (eds.) (2006), Production planning by mixed integer programming. New York, Springer-Verlag.

P. PESTIEAU (ed.) (2006), The welfare state in the European Union: economic and social perspectives. Oxford, Oxford University Press.

H. TULKENS (ed.) (2006), Public goods, environmental externalities and fiscal competition. New York, Springer-Verlag.

V. GINSBURGH and D. THROSBY (eds.) (2006), Handbook of the economics of art and culture. Amsterdam, Elsevier.

J. GABSZEWICZ (ed.) (2006), La différenciation des produits. Paris, La découverte.

L. BAUWENS, W. POHLMEIER and D. VEREDAS (eds.) (2008), High frequency financial econometrics: recent developments. Heidelberg, Physica-Verlag.

P. VAN HENTENRYCKE and L. WOLSEY (eds.) (2007), Integration of AI and OR techniques in constraint programming for combinatorial optimization problems. Berlin, Springer.

\section{CORE Lecture Series}

C. GOURIÉROUX and A. MONFORT (1995), Simulation Based Econometric Methods.

A. RUBINSTEIN (1996), Lectures on Modeling Bounded Rationality.

J. RENEGAR (1999), A Mathematical View of Interior-Point Methods in Convex Optimization.

B.D. BERNHEIM and M.D. WHINSTON (1999), Anticompetitive Exclusion and Foreclosure Through Vertical Agreements.

D. BIENSTOCK (2001), Potential function methods for approximately solving linear programming problems: theory and practice.

R. AMIR (2002), Supermodularity and complementarity in economics.

R. WEISMANTEL (2006), Lectures on mixed nonlinear programming. 
Département des Sciences Économiques de l'Université catholique de Louvain

Institut de Recherches Économiques et Sociales

Place Montesquieu, 3

1348 Louvain-la-Neuve, Belgique 